Nordic Concrete Research - Publ. No. NCR 60 - ISSUE 1 / 2019 - Article 9, pp. 145-158

\begin{tabular}{|c|c|}
\hline$S$ sciendo & 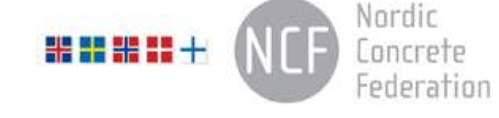 \\
\hline $\begin{array}{l}\text { (C) Article authors. This is an open access article distributed under } \\
\text { the Creative Commons Attribution-NonCommercial-NoDerivs } \\
\text { licens. (http://creaticecommons.org/licenses/by.nc-nd/3.0/). }\end{array}$ & $\begin{array}{l}\text { ISSN online } 2545-2819 \\
\text { ISSN print } \quad 0800-6377\end{array}$ \\
\hline DOI: $10.2478 /$ ncr-2019-0093 & $\begin{array}{r}\text { Received: Sept. 26, } 2018 \\
\text { Revision received: Feb. 1, } 2019 \\
\text { Accepted: June 18, } 2019\end{array}$ \\
\hline
\end{tabular}

\title{
Stability of Air Content in Fresh Concretes with PCE-Based Superplasticizers
}

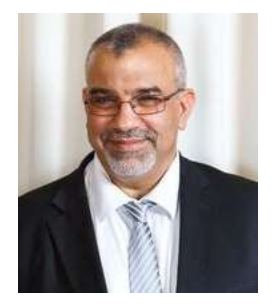

Fahim Al-Neshawy

D.Sc. (Tech.), Staff Scientist

Aalto University School of Engineering

Department of Civil Engineering

P.O.Box 12100, FIN-00076, Espoo, Finland

fahim.al-neshawy@aalto.fi

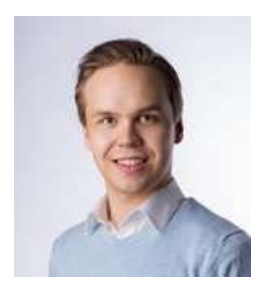

Teemu Ojala

M.Sc. Doctoral candidate

Aalto University School of Engineering

Department of Civil Engineering

P.O.Box 12100, FIN-00076, Espoo, Finland

teemu.ojala@aalto.fi

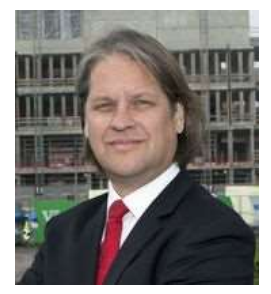

Jouni Punkki

D.Sc. (Tech.), Professor of Practice, Concrete Technology

Aalto University School of Engineering

Department of Civil Engineering

P.O.Box 12100, FIN-00076, Espoo, Finland

jouni.punkki@aalto.fi

\begin{abstract}
Air contents of concrete are necessary for concrete durability in freeze-thaw exposure. According to the Finnish concrete code, the target value for air content varies between $4 \%$ and $5.5 \%$ for XF - exposure classes. Lately in Finland, some cases showed an elevation of air contents up to $15 \%$ in fresh air-entrained concrete at construction site and in drilled concrete samples.
\end{abstract}

The objectives of this study were to investigate the stability of air entrainment by measuring the air content elevation 30 minutes and 60 minutes after concrete mixing and investigating the concrete sensitivity to segregation. Composition of concretes used in this study include 7 different combination of PCE based superplasticizer and air-entraining agent admixtures, cement content of $425 \mathrm{~kg} / \mathrm{m}^{3}$, two consistency classes S3 with water to cement ration of 0.33 and F5 with water 
to cement ration of 0.38 . One cement type was used for all concrete mixes. The concretes were mixed for 2 minutes and 5 minutes mixing times.

The results show that the elevation of the air content of fresh concrete depends on the consistency of the concrete and on the used combination of superplasticizer and air-entraining agents. The higher consistency classes concretes have more risk of air elevation with some combinations of PCE-based superplasticizers and air-entraining agents. The results also indicate that short mixing time would not be enough to achieve total effectivity of some air-entraining agents, especially for higher consistency classes concrete.

Key words: Air content, superplasticizer, air-entraining, admixtures, concrete.

1.

\section{INTRODUCTION}

In Finland, elevated air contents have been reported in air entrained concrete. The highest air contents determined from samples drilled from structures have exceeded $15 \%$ and significant deficiencies in compressive strength of the concrete have been reported. Some indications of elevated air contents have been seen during the last years, for example the railroad bridge in Kemijärvi [1] and the Turku University Hospital [2]. Concrete composition and consistency have been noticed to affect the air entrainment [3]. In addition, one critical factor could be the use of combination of air entraining agent (AEA) and the third generation polycarboxylate ether (PCE)based superplasticizers admixtures.

First-generation lignosulfonate-based superplasticizers (derived from the production of papermaking from wood) were air-entraining water-reducing agents. It was followed by the secondgeneration (early high-range) superplasticizers were derived from petroleum feed stocks: sulfonated naphthalene or melamine condensates with formaldehyde. The incorporation of second-generation superplasticizer lowers the viscosity of the fresh concrete mixture, thus facilitating the escape of air from it. Typically, $1 \%$ to $3 \%$ of the air is lost due to the addition of the admixture [4]. Third-generation Superplasticizers are polycarboxylates ethers (PCE), which are copolymers synthesized from carefully selected monomers.

Lazniewska (2009) reported that the air content in the presence of PCE superplasticizer increases with water to cement ratio as a sequence of the reduction of surface tension between the liquid and solid component of the paste [5]. It is complex to conclude what and how the chemical admixtures affect the air entrainment. Most organic chemical admixtures like PCE superplasticizer can increase the air entrainment since they can partly reduce the absorbed AEA molecules on the solid surface by competing with them. Other admixtures like retards, accelerators, etc., have minor effect on the air entrainment [3].

The action of the first and second-generation superplasticizers is based on electrostatic repulsion. The mechanism of those superplasticizers and air-entraining agent (AEA) working in the same cement paste is shown in Figure 1. With the present of SP, the air content tends to be reduced. The negative charged cement particles, given by the adsorption of SP molecules, prevent or lower the adsorption of AEA molecules. As a result, there is less space for air bubbles to be entrained. Also, the negative charge keeps cement particles and air bubbles dispersing from each other and then reduces the friction of the mix [7] and [8]. 

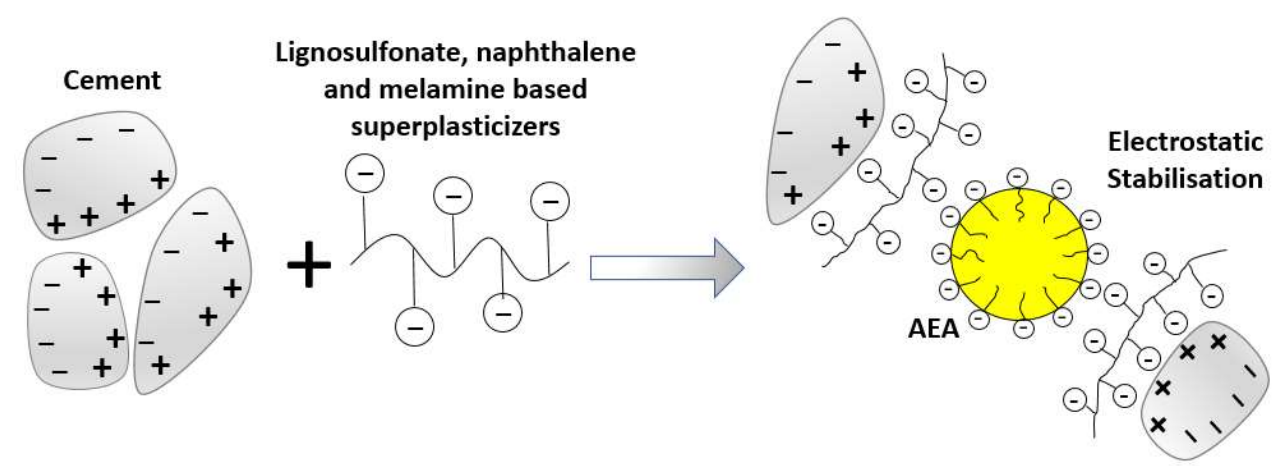

Figure 1 - Schematic draft showing electrostatic stabilization of cement and the mechanism of SP and AEA working in the same cement paste, adapted from [7] and [8].

The action of the polycarboxylate ethers (PCE) based superplasticizer cause a spatial (steric hindrance) separation of the cement particles, as shown in Figure 2. PCEs plasticizers have specific number of side chains that are distributed along a main chain. The carboxylate groups interact with the surface of the cement grain, which leads to polymer adsorption and a steric repulsion is considered as a potential mechanism of cement grains dispersion. [5], [6] and [7].

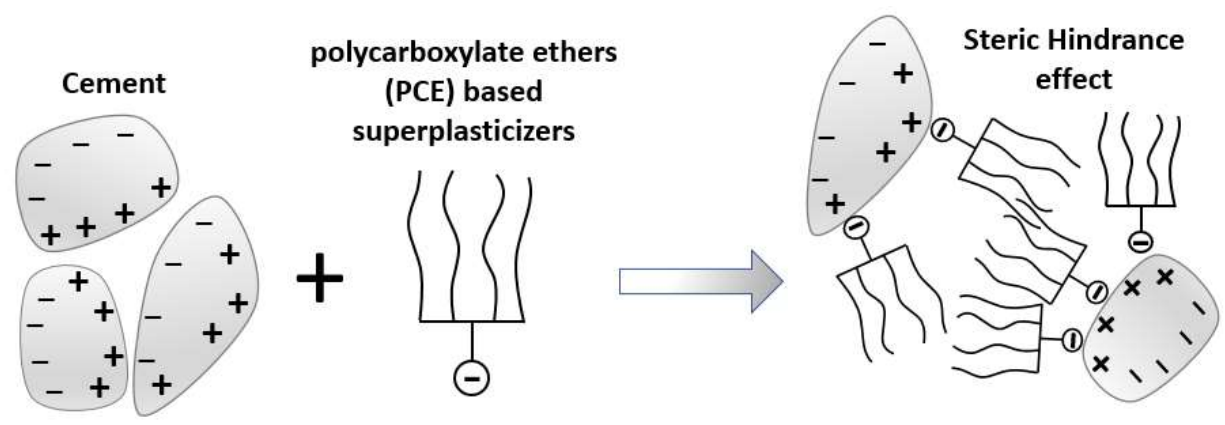

Figure 2 - Mechanism of polycarboxylate ethers (PCE) superplasticizer, adapted from [7].

Eickschen and Müller [9] investigated the action mechanisms occurring during the production of air-entrained concrete with plasticizers. Ten concretes (cement content $320 \mathrm{~kg} / \mathrm{m}^{3}$, w/c ratio 0.50 , air content of $5.5 \pm 0.5 \%$ and a consistency class F4) were produced in order to investigate the action mechanisms of air void formation in fresh and hardened concrete in relation to the combination of the air-entraining agent/plasticizer/cement starting materials. The concretes were produced with CEM I $42.5 \mathrm{~N}$ and CEM III/A $42.5 \mathrm{~N}-\mathrm{LH} / \mathrm{NA}$ cements (see Table 1) in combination with the following admixtures:

- Two types of air-entraining agents: (i) modified wood resin and (ii) synthetic tenside 1

- Three types of plasticizer: (i) pre-cast element, (ii) ready-mixed concrete PCE superplasticizer and (iii) plasticizer based on melamine sulfonate. 
Nordic Concrete Research - Publ. No. NCR 60 - ISSUE 1 / 2019 - Article 9, pp. 145-158

Table 1. Chemical and physical properties of the cement used in the Eickschen and Müller investigation [9]

\begin{tabular}{llcc}
\hline Parameter & & CEM I 42.5 R & CEM III/A 42.5 N-LH/NA \\
\hline $\mathrm{K}_{2} \mathrm{O}$ & mass\% & 0.88 & 0.91 \\
$\mathrm{Na}_{2} \mathrm{O}$ & mass $\%$ & 0.13 & 0.23 \\
$\mathrm{Na}_{2} \mathrm{O}$ equiv. & mass\% & 0.71 & 0.83 \\
$\mathrm{SO}_{3}$ & mass\% & 2.96 & 2.90 \\
$\mathrm{BFS}$ content & mass\% & - & 50.6 \\
Initial setting & min & 160 & 220 \\
time & & 27 & 30 \\
Water demand & $\%$ & 3250 & 4210 \\
Spec. surface & $\mathrm{cm}^{2} / \mathrm{g}$ & & \\
area & & $2 \mathrm{~d}=25.1$ & $2 \mathrm{~d}=17.0$ \\
Compressive & $\mathrm{N} / \mathrm{mm}^{2}$ & $7 \mathrm{~d}=42.4$ & $7 \mathrm{~d}=34.6$ \\
strength & & $28 \mathrm{~d}=56.5$ & $28 \mathrm{~d}=52.1$ \\
\hline
\end{tabular}

The influence of the plasticizer on the air content of concrete with CEM I and CEM III binders is shown in Figure 3. Eickschen and Müller [9] concluded that the increase in air content was substantially greater than with the natural air-entraining agent. The increase in air content was more strongly marked when using the PCE-based plasticizers than with the conventional plasticizers (melamine sulfonate). Combinations with the synthetic air-entraining agent and a PCE-based plasticizer exhibited a greater range of fluctuation in air content than combinations with natural air-entraining agents and conventional plasticizers.

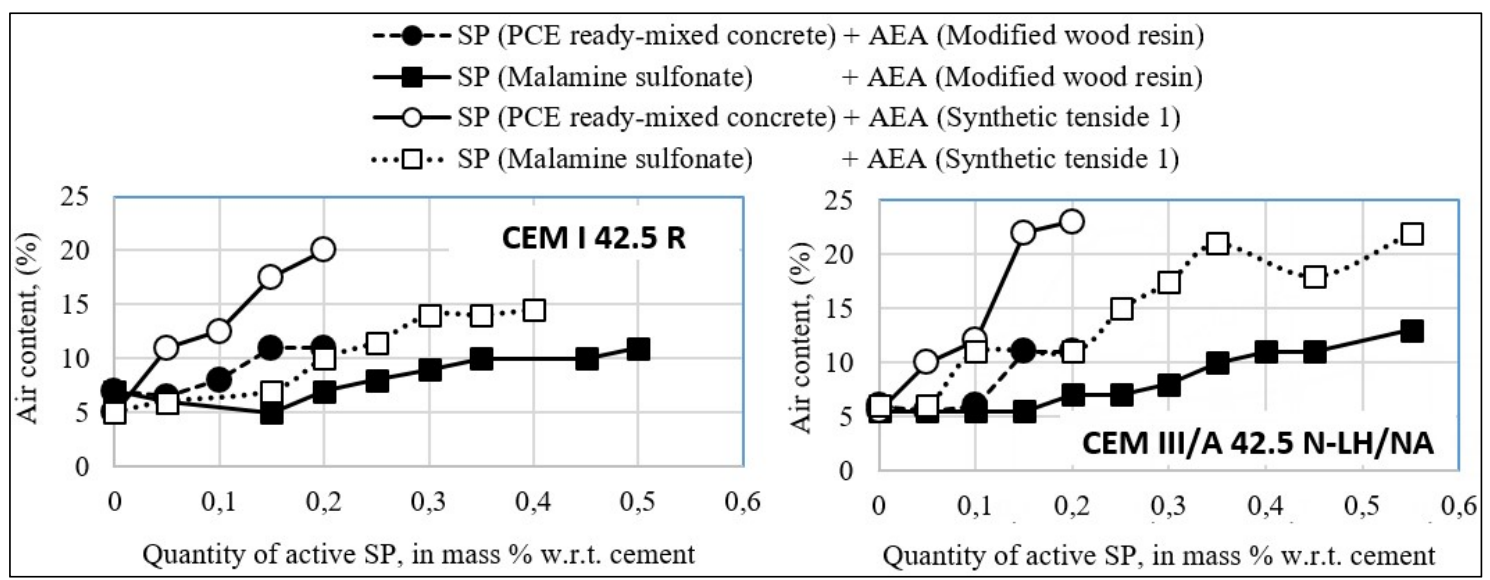

Figure 3 - The effect of the type and the quantity of superplasticizer on the air content of concrete mixtures using CEM I and CEM III cements and different types of Air-Entraining Agents. The chart data are based on Eickschen and Müller (2012) results. [9].

Based on the recent Finnish cases of Kemijärvi [1] and [2], the air content may elevate after mixing and causes strength problems. The aim of the study was to investigate and secure the stability of the protective pore system in air entrained concrete and thereby reduce the risk for elevated air contents in concrete structures.

The authors believe that the air content potential phenomenon is the reason for the elevated air content. It is explained by the maximum potential air content which depends on the admixture combination, concrete composition and the consistency of concrete. It is possible that only part of 
the entrained air is formed during the normal mixing process, especially when the mixing time is short, and more air is formed in the concrete truck mixers. A relative effective mixing process is needed to achieve the air content potential during the mixing process.

The risk for elevated air contents can be reduced by using longer mixing time. Then also the dosage of air-entraining agents can be reduced.

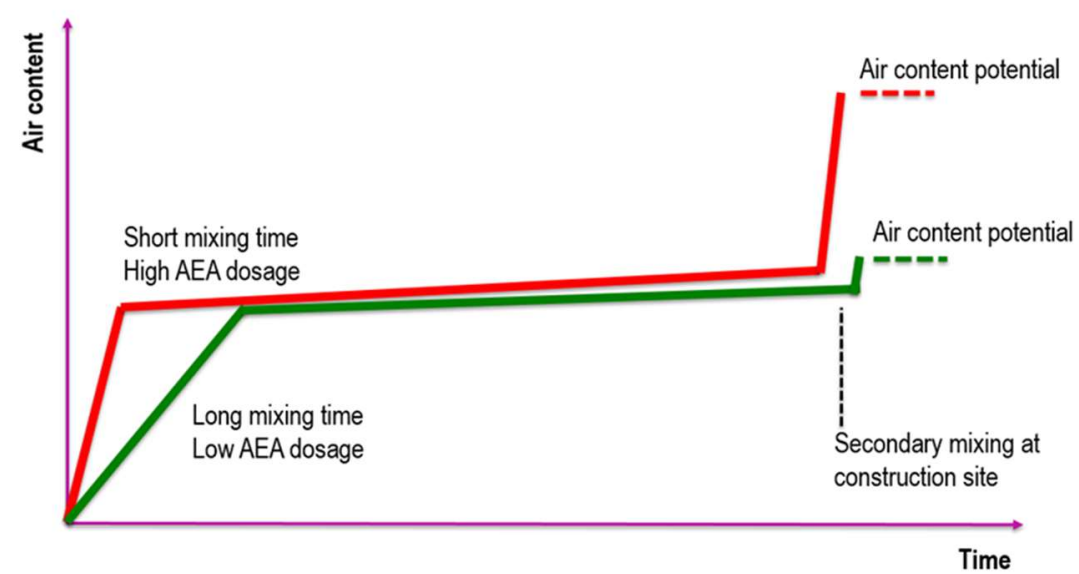

Figure 4 - Illustrated effects of the mixing time (mixing efficiency) and the AEA dosage on the increase of the air content after mixing [10].

\section{MATERIALS AND METHODS}

The aim of the investigation was to clarify the factors affecting the stability of the air entrainment in fresh content. The factors investigated were (i) the concrete composition and (ii) combination of different superplasticizers and air-entraining agents.

To carry out the investigation, concrete mixtures with different types of AEAs and PCE-based superplasticizers were prepared and the stability of entrained air was evaluated. The following variables were tested:

i. Concrete composition factors: air content of concrete, consistency of concrete and mixing time.

ii. Chemical admixture (SP + AEA) combinations from seven different admixture producers were investigated. All the superplasticizers tested were polycarboxylate ethers.

Effects of the above-mentioned variables on the air content of concrete at different times after mixing were analyzed. The air content was measured immediately after mixing, 30 minutes and 60 minutes after mixing. In addition, after 60 minutes superplasticizer was added to compensate the workability loss and air content were measured after 75 minutes after mixing. Also, the density variation of the concrete was monitored [10].

The laboratory investigations were carried out with a typical concrete composition for structural concrete. The properties of the investigated concrete were:

- Compressive strength class: C35/45-P50 (P-factor is a value used to evaluate the freeze-thaw resistance in the Finnish codes and standards) [11]. 
Nordic Concrete Research - Publ. No. NCR 60 - ISSUE 1 / 2019 - Article 9, pp. 145-158

- $\quad$ Consistency of concrete: two classes (F5 and S3)

- $\quad$ Maximum aggregate size: $16 \mathrm{~mm}$

- $\quad$ Cement type: Plus Cement (CEM II/B-M (S-LL) 42,5 N) produced by Finnsementti's cement plant at Parainen, Finland

Totally seven different SP and AEA admixture combinations were tested. The properties of the PCE superplasticizers used in the tests are presented in Table 1. The concrete mix design is presented in Table 2.

Table 2 - Properties of the polycarboxylate ether based superplasticizers used in the tests.

\begin{tabular}{lcccc}
\hline Superplasticizer & $\begin{array}{c}\text { Density, } \\
\left(\mathrm{g} / \mathrm{cm}^{3}\right)\end{array}$ & $\mathrm{pH}$ & $\begin{array}{c}\text { Chloride content, } \\
(\%)\end{array}$ & $\begin{array}{c}\text { Alkali content, } \\
(\%)\end{array}$ \\
\hline $\mathrm{A}$ & $1.03 \pm 0.02$ & 5.5 & $<0.02$ & $<2.0$ \\
$\mathrm{~B}$ & 1.03 & $6.0-8.0$ & $<0.1$ & $\leq 2.0$ \\
$\mathrm{C}$ & 1.055 & 4.3 & $<0.1$ & $<1.0$ \\
$\mathrm{D}$ & $1.07 \pm 0.02$ & 0.3 & $<0.10$ & $<4.0$ \\
$\mathrm{E}$ & $1.05 \pm 0.02$ & 6.0 & $<0.05$ & $<2.0$ \\
$\mathrm{~F}$ & $1.05 \pm 0.02$ & 0.3 & $<0.05$ & $<2.0$ \\
$\mathrm{G}$ & $1.04 \pm 0.02$ & 7.0 & $<0.0015$ & $\geq 0.5$ to $<1$ \\
\hline
\end{tabular}

Table 3 - Mix design of concretes with different admixtures. (A to $G$ are the combinations of chemical admixtures, $S 3$ and $F 5$ are the consistency classes of the concrete).

\begin{tabular}{lccccccccc}
\hline $\begin{array}{l}\text { Mix } \\
\text { code }\end{array}$ & $\begin{array}{c}\text { Cement } \\
\left(\mathrm{kg} / \mathrm{m}^{3}\right)\end{array}$ & $\begin{array}{c}\text { Effect. } \\
\text { water } \\
\left(\mathrm{kg} / \mathrm{m}^{3}\right)\end{array}$ & $\begin{array}{c}\text { (w/c) })_{\text {eff }} \\
\text { Aggreg. } \\
\left(\mathrm{kg} / \mathrm{m}^{3}\right)\end{array}$ & $\begin{array}{c}\text { AEA, } \\
\left(\mathrm{kg} / \mathrm{m}^{3}\right)\end{array}$ & $\begin{array}{c}\text { AEA } \\
\text { w.r.t. } \\
\text { cement } \\
(\%)\end{array}$ & $\begin{array}{c}\text { SP, } \\
\left(\mathrm{kg} / \mathrm{m}^{3}\right)\end{array}$ & $\begin{array}{c}\text { SP.r.t. } \\
\text { cement } \\
(\%)\end{array}$ & $\begin{array}{c}\text { Target } \\
\text { air } \\
\text { content } \\
(\%)\end{array}$ \\
\hline A-S3 & 425 & 140 & 0.33 & 1716 & 0.15 & 0.04 & 5.10 & 1.20 & 5.5 \\
A-F5 & 425 & 160 & 0.38 & 1770 & 0.15 & 0.04 & 5.10 & 1.20 & 5.5 \\
B-S3 & 425 & 140 & 0.33 & 1716 & 0.15 & 0.04 & 6.29 & 1.48 & 5.5 \\
B-F5 & 425 & 160 & 0.38 & 1766 & 0.23 & 0.06 & 5.10 & 1.20 & 5.5 \\
C-S3 & 425 & 140 & 0.33 & 1720 & 0.21 & 0.05 & 5.19 & 1.22 & 5.5 \\
C-F5 & 425 & 160 & 0.38 & 1772 & 0.38 & 0.09 & 3.40 & 0.80 & 5.5 \\
D-S3 & 425 & 140 & 0.33 & 1718 & 0.20 & 0.05 & 4.76 & 1.12 & 5.5 \\
D-F5 & 425 & 160 & 0.38 & 1768 & 0.42 & 0.10 & 4.34 & 1.02 & 5.5 \\
E-S3 & 425 & 140 & 0.33 & 1717 & 0.32 & 0.08 & 5.44 & 1.28 & 5.5 \\
E-F5 & 425 & 160 & 0.38 & 1770 & 0.81 & 0.19 & 3.83 & 0.90 & 5.5 \\
F-S3 & 425 & 140 & 0.33 & 1715 & 0.81 & 0.19 & 4.12 & 0.97 & 5.5 \\
F-F5 & 425 & 160 & 0.38 & 1767 & 0.26 & 0.06 & 5.65 & 1.33 & 5.5 \\
G-S3 & 425 & 140 & 0.33 & 1716 & 0.85 & 0.20 & 3.61 & 0.85 & 5.5 \\
G-F5 & 425 & 160 & 0.38 & 1770 & 0.34 & 0.08 & 4.85 & 1.14 & 5.5 \\
\hline
\end{tabular}

The aggregates used in these tests were granitic gravel, which were washed, dried and graded by sieving. The grading curve of the combined aggregate is presented in Figure 5. 
Nordic Concrete Research - Publ. No. NCR 60 - ISSUE 1 / 2019 - Article 9, pp. 145-158

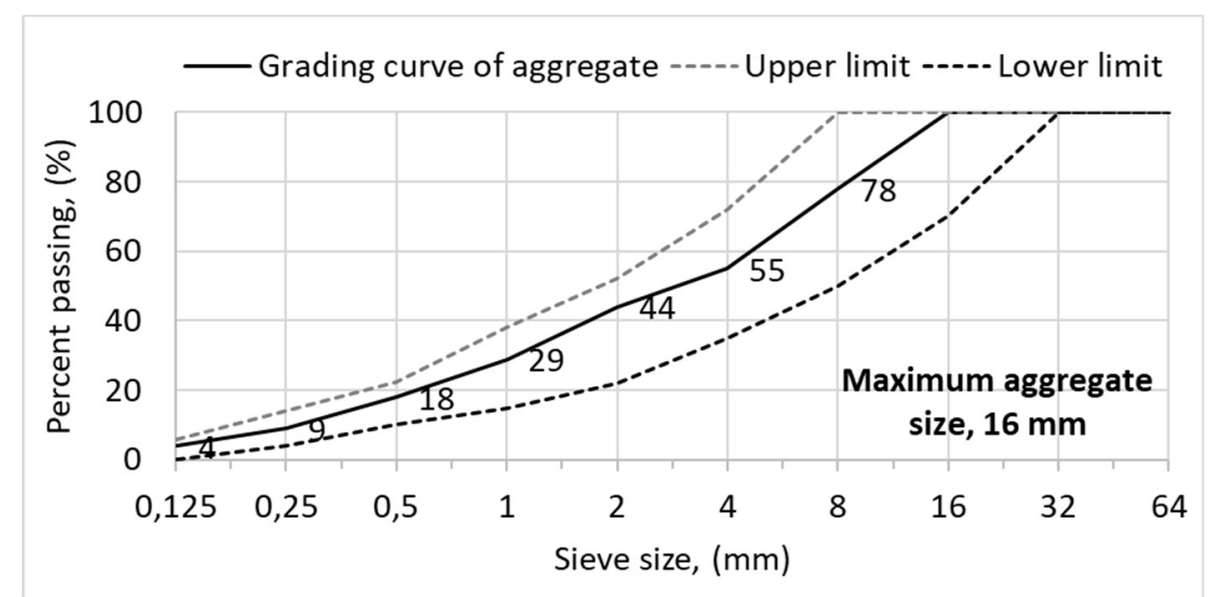

Figure 5 - Combination of aggregates used for the experimental tests.

The properties determined on fresh concrete were air content, density, temperature and consistency. Air-content of concrete was measured by the following methods: (i) pressure method according to the European standard SFS-EN 12350-7 [12] and (ii) Calculated from the fresh concrete unit weight. The air content of fresh concrete was calculated according to the ASTM C 138 - standard [13].

where:

$$
\text { Air content, } A=\frac{(T-D)}{T} \times 100
$$

$A=$ the air content in the concrete, $(\%)$

$D=$ the density (unit weight) of concrete, $\left(\mathrm{kg} / \mathrm{m}^{3}\right)$

$T=$ the theoretical density of the concrete computed on air free bases, $\left(\mathrm{kg} / \mathrm{m}^{3}\right)$

$$
T=\frac{M}{V}=\frac{M}{1-A_{t}}
$$

where:

$M=$ the mass of all materials batched - sum of the masses of the cement, the aggregates, the mixing water and the chemical admixtures, $(\mathrm{kg})$.

$V=$ the absolute volume of the component ingredients in the batch, $\left(\mathrm{m}^{3}\right)$

$A_{t}=$ the target air content of the batch, $\left(\mathrm{m}^{3}\right)$

Based on Equations (1) and (2), the air content is calculated as follow:

$$
\text { Air content, } A=\left(1-\frac{D}{M}+\frac{D \times A_{t}}{M}\right) \times 100
$$

The workability of concrete was tested using two standards: (i) SFS-EN 12350-2 [14] and (ii) SFS-EN 12350-5 [15]. The measurements of fresh concrete properties took place immediately after the concrete had been mixed, after 30 minutes, after 60 minutes and after 75 minutes. The workability of concretes as function of time is presented in Table 4. 
Nordic Concrete Research - Publ. No. NCR 60 - ISSUE 1 / 2019 - Article 9, pp. 145-158

Table 4-Workability of S3 - class and F5 concretes as function of time.

\begin{tabular}{|c|c|c|c|c|c|c|c|}
\hline \multirow{2}{*}{$\begin{array}{l}\text { Concrete } \\
\text { mix }\end{array}$} & \multicolumn{3}{|c|}{$\begin{array}{c}\text { Time after mixing } \\
\text { (min) }\end{array}$} & \multicolumn{2}{|c|}{ Workability loss } & \multicolumn{2}{|c|}{$\begin{array}{l}\text { Workability gain after } \\
\text { adding extra SP dosage }\end{array}$} \\
\hline & 0 min & $30 \mathrm{~min}$ & $60 \mathrm{~min}$ & $30 \mathrm{~min}$ & $60 \mathrm{~min}$ & $\begin{array}{l}\text { SP dosage / } \\
\text { cement }(\%)\end{array}$ & $75 \mathrm{~min}$ \\
\hline \multicolumn{8}{|c|}{ Slump test for $\mathrm{S} 3$ class concretes, $(\mathrm{mm})$} \\
\hline A-S3 & 130 & 20 & 10 & $85 \%$ & $92 \%$ & 0,018 & 60 \\
\hline B-S3 & 80 & 10 & 0 & $88 \%$ & $100 \%$ & 0,022 & 30 \\
\hline $\mathrm{C}-\mathrm{S} 3$ & 170 & 40 & 30 & $76 \%$ & $82 \%$ & 0,013 & 130 \\
\hline D-S3 & 160 & 110 & 50 & $31 \%$ & $69 \%$ & 0,017 & 190 \\
\hline E-S3 & 110 & 90 & 60 & $18 \%$ & $45 \%$ & 0,019 & 220 \\
\hline F-S3 & 150 & 60 & 70 & $60 \%$ & $53 \%$ & 0,015 & 220 \\
\hline G-S3 & 120 & 80 & 40 & $33 \%$ & $67 \%$ & 0,021 & 180 \\
\hline \multicolumn{8}{|c|}{ Flow table test for $\mathbf{F 5}$ class concretes, $(\mathrm{mm})$} \\
\hline A-F5 & 590 & 450 & 390 & $24 \%$ & $34 \%$ & 0,018 & 620 \\
\hline B-F5 & 500 & 490 & 460 & $2 \%$ & $8 \%$ & 0,019 & 500 \\
\hline C-F5 & 520 & 390 & 340 & $25 \%$ & $35 \%$ & 0,011 & 520 \\
\hline D-F5 & 660 & 610 & 510 & $8 \%$ & $23 \%$ & 0,018 & 700 \\
\hline E-F5 & 560 & 480 & 480 & $14 \%$ & $14 \%$ & 0,016 & 700 \\
\hline F-F5 & 570 & 500 & 470 & $12 \%$ & $18 \%$ & 0,015 & 700 \\
\hline G-F5 & 570 & 520 & 480 & $9 \%$ & $16 \%$ & 0,020 & 640 \\
\hline
\end{tabular}

The following hardened concrete tests were performed: (i) $28 \mathrm{~d}$ compressive strength tests on three cubes $\left(100 \times 100 \times 100 \mathrm{~mm}^{3}\right)$ cast immediately after concrete mixing and three cubes cast after 75 minutes of mixing and addition of extra dosage of superplasticizer and (ii) segregation sensitivity of concrete presented by the air content and paste content difference between bottom and top parts of $150 \mathrm{~mm}$ diameter concrete cylinder with height of about 270-300 $\mathrm{mm}$, presented in Figure 6.

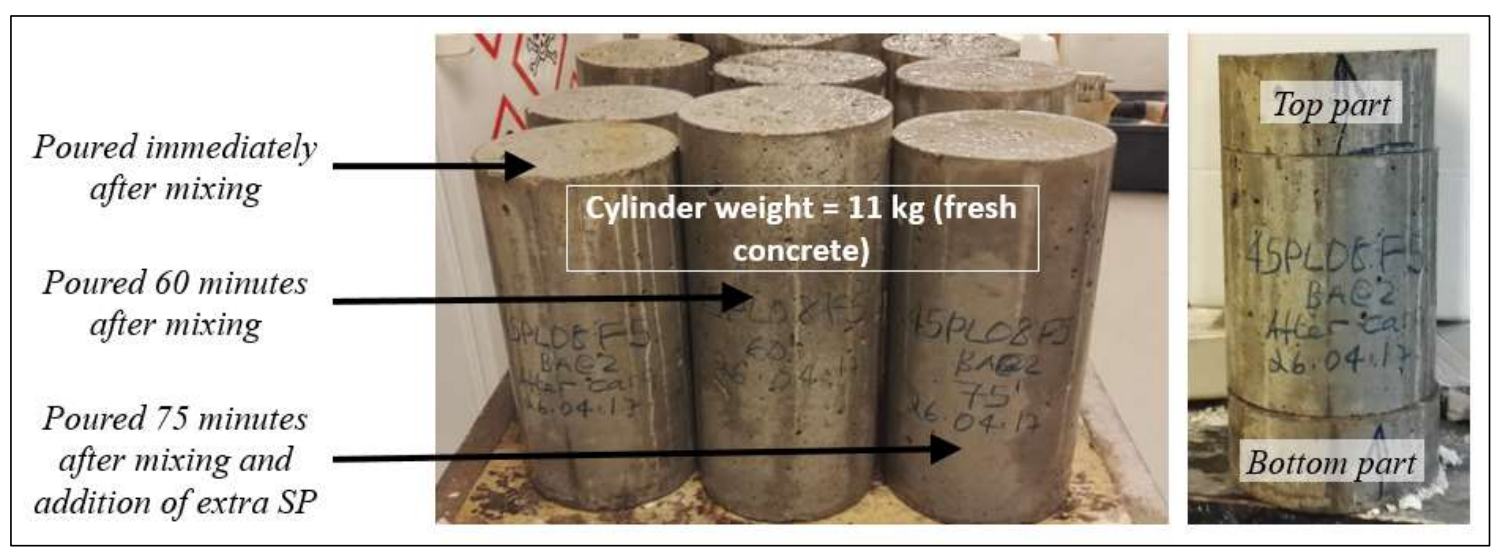

Figure 6 - Example of the specimens used for sensitivity of concrete for segregation test. The same mass of concrete results different heights for the test specimens, which indicates different air contents. 


\section{3.}

\section{EXPERIMENTAL RESULTS AND DISCUSSION}

The mixing procedure of the concrete the following steps (i) dry mixing of cement and aggregates for 30 seconds, (ii) addition of $80 \%$ of the water content, (iii) after 30 seconds, addition of $10 \%$ of the water content and the AEA, (iii) after another 30 seconds, addition of $10 \%$ of the water content and the superplasticizer and continue mixing for 1 minute. The air content of fresh concretes with different chemical admixtures was measured immediately after mixing, at 30 minutes, at 60 minutes and 75 minutes after mixing. An extra dosage of superplasticizers was added and concrete was mixed for 2 min before measuring the air content at 75 minutes. The calculated air contents of all the test concretes are presented in Figure 7, Figure 8, Table 5 and Table 6.

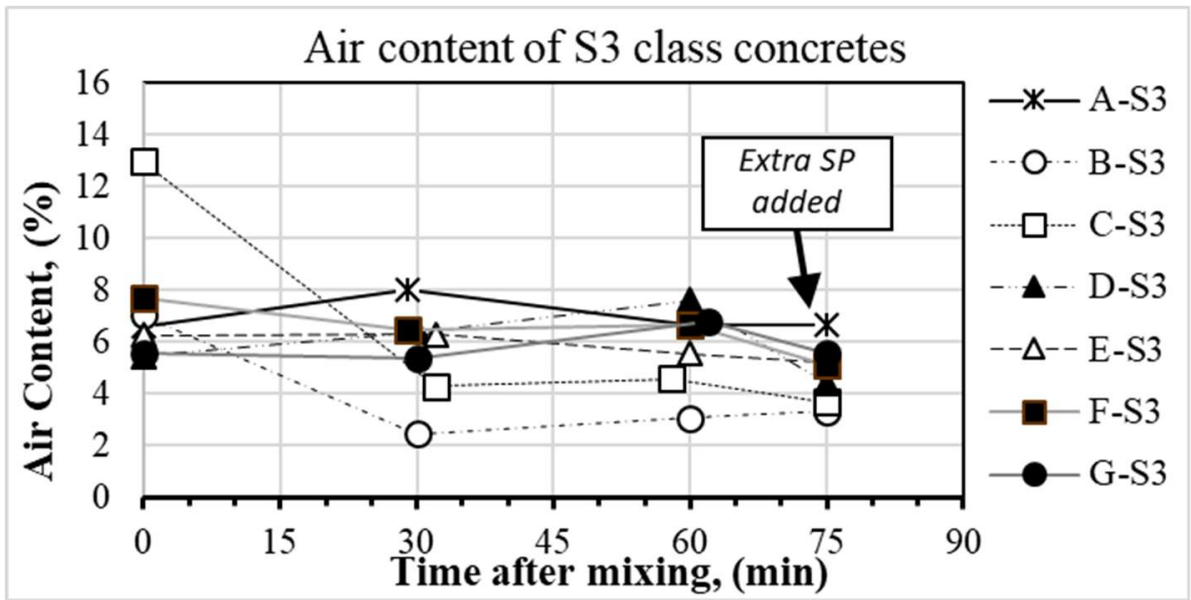

Figure 7 - Calculated air contents of the S3 consistency class concretes. The calculation is based on the fresh concrete density (unit weight)

Table 5 - Air content and air content - elevation for S3 consistency class concretes.

\begin{tabular}{ccccccccc}
\hline \multirow{2}{*}{ Concrete code } & \multicolumn{8}{c}{ Air content, (\%) } \\
& A-F3 & B-F3 & C-F3 & D-F3 & E-F3 & F-F3 & G-F3 \\
\hline Time & 0 & 6.6 & 7.0 & 13.0 & 5.5 & 6.3 & 7.7 & 5.6 \\
after & $30 \pm 2$ & 8.0 & 2.5 & 4.3 & 6.4 & 6.3 & 6.5 & 5.4 \\
mixing, & $60 \pm 2$ & 6.7 & 3.1 & 4.6 & 7.6 & 5.6 & 6.7 & 6.8 \\
(min) & $75 \pm 2$ & 6.7 & 3.3 & 3.7 & 4.4 & 5.2 & 5.1 & 5.6 \\
\hline \multicolumn{7}{c}{ Air content - elevation, (\%) } \\
\hline 30 min after mixing & 1.4 & -4.6 & -8.6 & 0.9 & 0.0 & -1.2 & -0.2 \\
60 min after mixing & 0.1 & -4.0 & -8.4 & 2.2 & -0.7 & -1.0 & 1.2 \\
\hline
\end{tabular}


Nordic Concrete Research - Publ. No. NCR 60 - ISSUE 1 / 2019 - Article 9, pp. 145-158

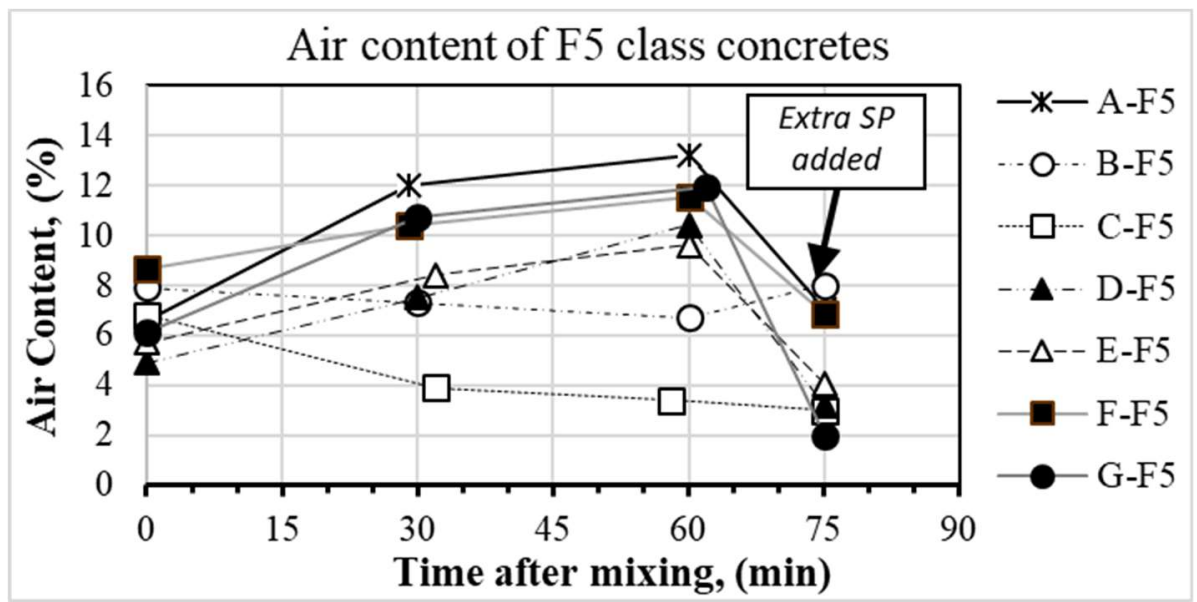

Figure 8-Calculated air contents of the F5 consistency class concretes.

Table 6-Air content and air content - elevation for F5 consistency class concretes.

\begin{tabular}{ccccccccc}
\hline \multirow{2}{*}{ Concrete code } & \multicolumn{7}{c}{ Air content, (\%) } \\
& A-F5 & B-F5 & C-F5 & D-F5 & E-F5 & F-F5 & \multirow{2}{*}{ G-F5 } \\
\hline Time & 0 & 6.6 & $\mathbf{7 . 9}$ & $\mathbf{6 . 8}$ & 4.9 & 5.7 & 8.6 & 6,1 \\
after & $30 \pm 2$ & 12.0 & $\mathbf{7 . 3}$ & $\mathbf{3 . 9}$ & 7.5 & 8.4 & 10.4 & 10,7 \\
mixing, & $60 \pm 2$ & 13.2 & $\mathbf{6 . 7}$ & $\mathbf{3 . 4}$ & 10.4 & 9.6 & 11.5 & 11,9 \\
(min) & $75 \pm 2$ & 7.1 & $\mathbf{8 . 0}$ & $\mathbf{3 . 0}$ & 3.2 & 4.1 & 6.9 & 2.0 \\
\hline \multicolumn{7}{c}{ Air content - elevation, (\%) } \\
\hline 30 min after mixing & 5.4 & $\mathbf{- 0 . 5}$ & $\mathbf{- 3 . 0}$ & 2.6 & 2.7 & 1.8 & 4.6 \\
60 min after mixing & 6.6 & $\mathbf{- 1 . 2}$ & $\mathbf{- 3 . 4}$ & 5.5 & 3.9 & 2.8 & 5.7 \\
\hline
\end{tabular}

The results show that the elevation of the air content of fresh concrete depends on the consistency of the concrete and on the type of superplasticizer used. The air content-elevation was higher for the consistency class F5 concretes where the workability loss after 30 and 60 minutes was lower as presented in Table 4, except for the combination of A and B superplasticizer the air content decreases at 30 and 60 minutes after mixing. The elevation of air content in the consistency class S3 concrete was not significant as the consistency class F5 concretes. As shown in Figure 9, the consistency class plays an important role, S3 class concrete showed smaller air content elevation for some combination of AEA and superplasticizers compared to F5 class concrete.

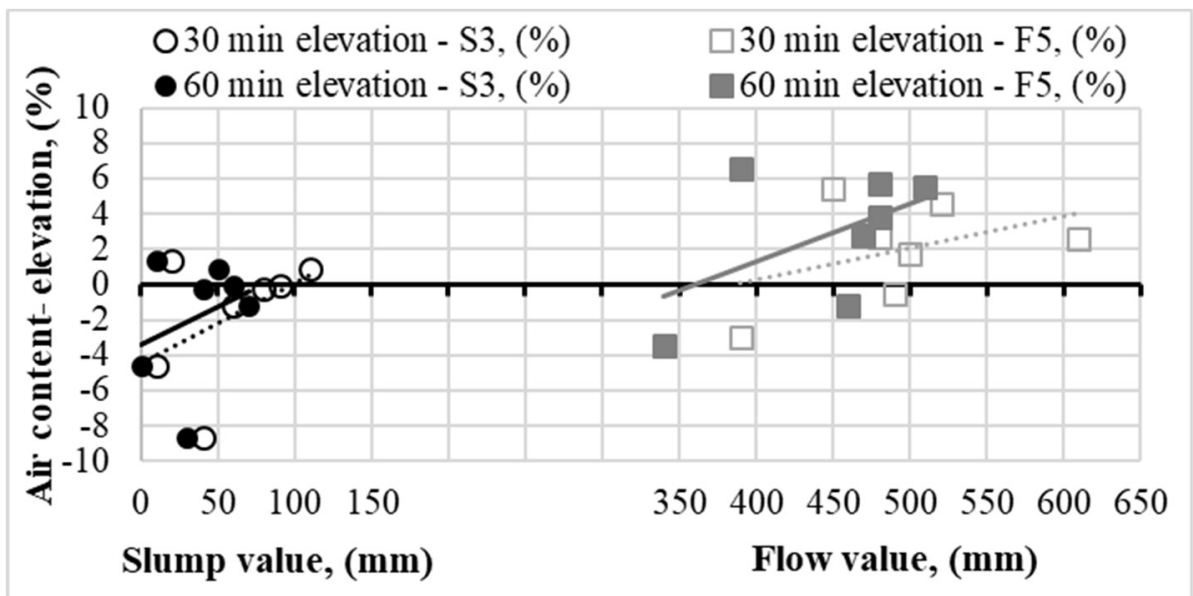

Figure 9 - The effect of the concrete consistency on the air content-elevation of concrete. 
The test results indicated that the air content increases after initial mixing. A relatively high superplasticizer dosage ( $1.2 \%$ from weight of cement) was used. With lower dosages, the increase will probably be smaller. The consistency was determined immediately after mixing, whereas in practical applications the consistency of concrete is generally determined on construction site, it means some $15 \ldots 60 \mathrm{~min}$ after the initial mixing. Therefore, the consistency immediately after mixing was lower compared to that found typically in the industry.

The admixtures dosages varied to some extent. It could be assumed that higher admixture dosages increase risk for the elevated air content. The effects of superplasticizers dosages on the increase of air content of concrete are presented in Figure 10. The slightly different admixture dosages used in the study did not explain the increase of air content. However, if admixture dosages would vary on the lager range, the situation could be different.

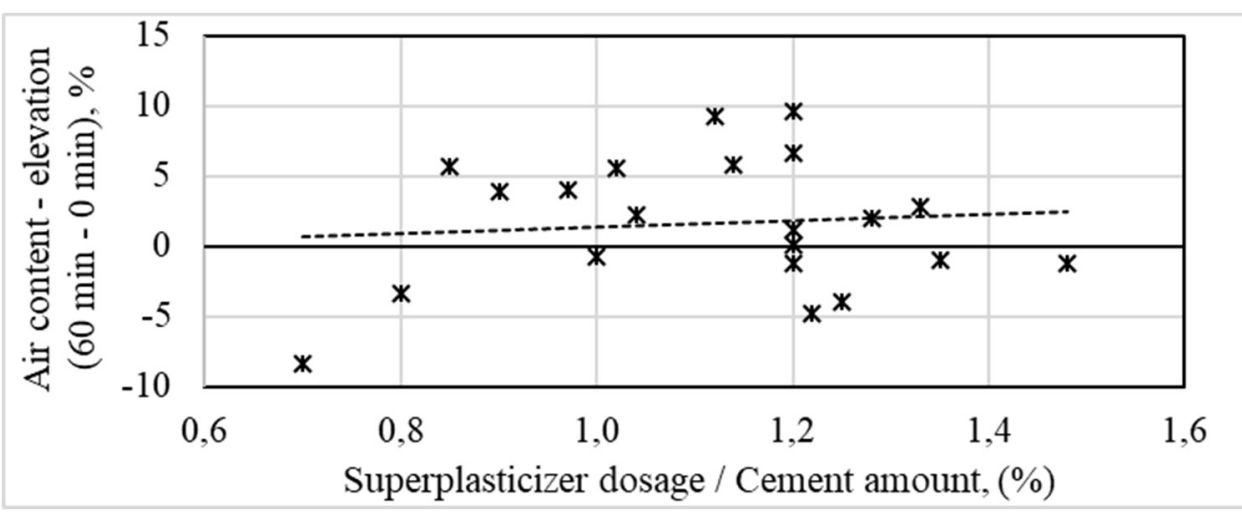

Figure 10 - Effects of superplasticizer dosage on the elevation of air content in concrete.

The sensitivity of segregation investigation were carried out on the hardened specimens that were cast immediately after mixing. The sensitivity of segregation was analyzed by comparing the densities of the bottom and top part of the cylindrical test specimens, shown in Figure 11.

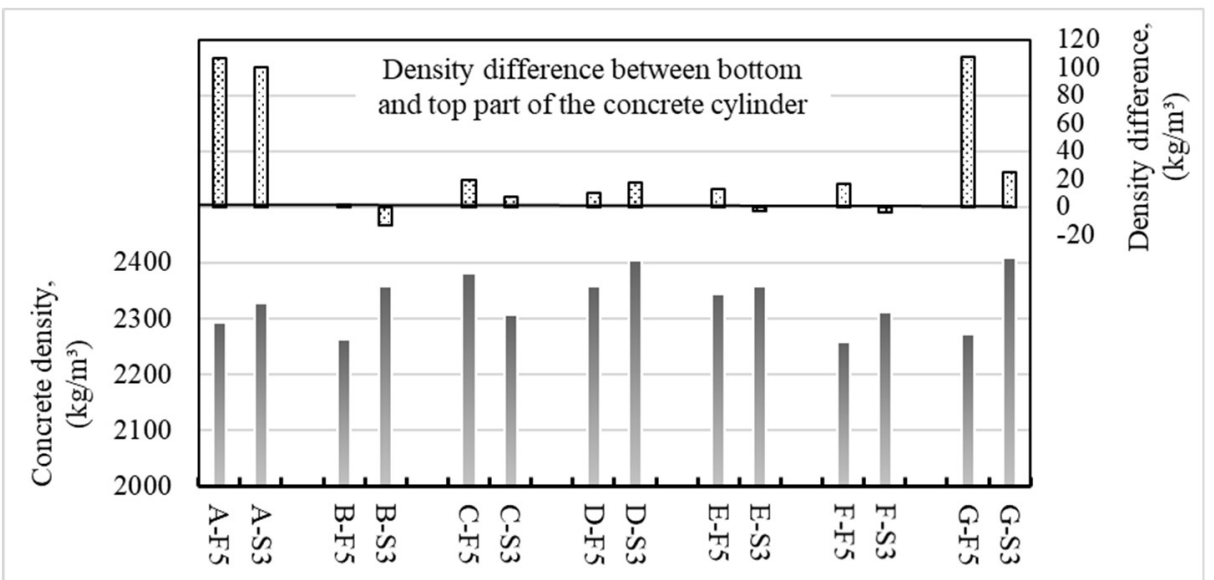

Figure 11 - Density differences of hardened concretes poured immediately after mixing for concrete mixes with different chemical admixtures combinations.

$11 \mathrm{~kg}$ of fresh concrete was poured inside a $150 \mathrm{~mm}$ diameter and a $300 \mathrm{~mm}$ high cylindrical steel moulds and immediately vibration was applied using vibrating table for 30 seconds. The density differences between different parts of the hardened concrete cylinder are shown in Figure 11. 
The results of the effects of air content increment on the segregation sensitivity of concrete show a slight correlation between the increase of air content and the density difference can be observed for the using of the chemical admixture combination $A$ and $G$, otherwise the effect was not significant. With admixture combination $A$ and $\mathrm{G}$, a difference of about $100 \mathrm{~kg} / \mathrm{m}^{3}$ was exceeded, but other admixture combinations gave only very small difference. The results also show that the S3 consistency class concrete showed smaller segregation sensitivity compared to F5 class concrete for most types of admixtures.

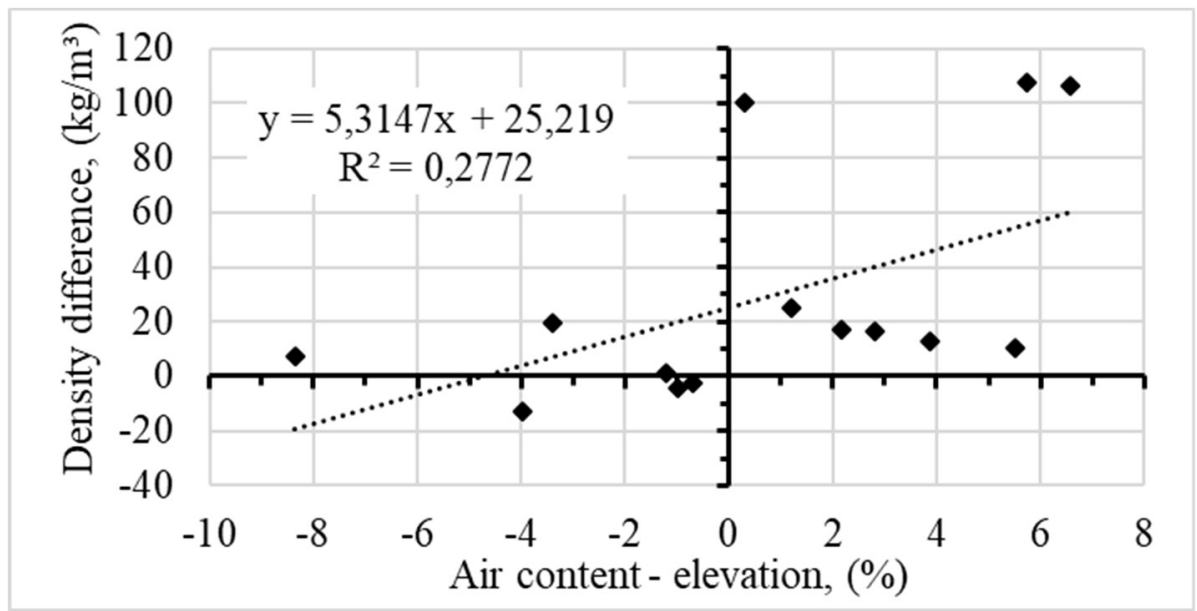

Figure 12 - The effects of air content increment of the density difference between the top and bottom parts of concrete specimens that were cast immediately after mixing and compacted for $30 \mathrm{sec}$.

As shown in Figure 12, the density difference appears to correlate with the increase of the air content after mixing. The correlation is not strong, but in most cases, the same admixtures gave both high increase of air content and high-density difference.

The effect of the mixing time on the air content of concrete with different chemical admixture combinations is presented in Table 7 . The results show that 2 minute mixing time (which simulate the concrete industry practices) gives lower air content than 5 minute mixing time immediately after mixing. While, the air contents for both mixing times measured at 60 minutes after mixing were close to each other, except for the $\mathrm{G}$ admixture combination. The results indicate that short mixing time would not be enough to achieve total effectivity of AEA, especially for higher consistency classes concrete. 
Nordic Concrete Research - Publ. No. NCR 60 - ISSUE 1 / 2019 - Article 9, pp. 145-158

Table 7 - The effect of mixing time on the air content potential of concrete, using pressure method.

$$
\text { Air content, (\%) }
$$

Concrete code

Time after mixing, $(\mathrm{min})$

$\begin{array}{lll}0 & 30 \pm 2 & 60 \pm 2\end{array}$

A-F5 (mixing 2 minutes)

6.0

10.4

11.4

A-F5 (mixing 5 minutes)

10.0

11.7

11.4

B-F5 (mixing 2 minutes)

5.6

8.0

8.5

B-F5 (mixing 5 minutes)

8.1

9.0

7.6

C-F5 (mixing 2 minutes)

4.0

7.7

10.6

C-F5 (mixing 5 minutes)

8.0

10.6

12.0

D-F5 (mixing 2 minutes)

4.1

6.5

8.4

D-F5 (mixing 5 minutes)

5.6

7.6

8.8

E-F5 (mixing 2 minutes)

4.5

6.8

8.4

E-F5 (mixing 5 minutes)

4.6

7.1

9.0

F-F5 (mixing 2 minutes)

6.1

7.9

10.5

F-F5 (mixing 5 minutes)

8.2

9.8

12.0

G-F5 (mixing 2 minutes)

5.9

3.2

3.1

G-F5 (mixing 5 minutes)

3.3

3.5

\section{4.}

\section{SUMMARY AND CONCLUSION}

A number of concrete tests were carried out to analyze the effect of superplasticizers on the stability of the protective pore systems. Clear increase of the air content after the initial mixing of concrete was observed, the highest measured air contents were close to $13 \%$, while the air content after mixing was $6.6 \%$.

The increase of air content is a complex issue and several factors are affecting the phenomenon. However, based on the tests the increase of the air content after the initial mixing can be explained as follows:

1. The air content depends on the admixture combination (superplasticizer, air entraining agent and their dosage).

2. The consistency of concrete has a big role in the air content elevation of concrete in relation to different chemical admixture combination.

3. Initial mixing time also affects the air content elevation of concrete. A mixing time of 2 minutes was too short achieve the full potential air content.

The authors believe that there are probably other aspects affecting the air content elevation of fresh concrete, which could be a topic for future investigation. Occasionally air content continues increasing after initial mixing even though the initial mixing time has been rather long. In such cases, the superplasticizer is probably playing the major role, the foam killer may lose its power and air content is increasing.

\section{REFERENCES}

1. Mölsä S: “The reason for the Kemijärvi railroad bridge's construction defects". 2016. (In Finnish). [Online] https://www.rakennuslehti.fi/2016/11/kemijarven-sillan-valuvian-syytselvisivat-turkua-tutkitaan/ [Accessed on 29.1.2019] 
2. Turunsanomat News: "The background of the concrete strength problems is the elevated air content in-site". 2016. (In Finnish). [Online] https://www.ts.fi/uutiset/paikalliset/3117381/Betonin+lujuusongelmien+taustalla+liialliset +ilmamaarat+Tyksin+tyomaalla [Accessed on 29.1.2019]

3. Yang Q: "Stability of air bubbles in fresh concrete". Master of Science Thesis. Department of Civil and Environmental Engineering, Division of Building Technology. Chalmers University of Technology, Göteborg, Sweden, 2012.

4. Zakka A, Carrasquillo R \& Ramon L: "Effects of high-range water reducers on the properties of fresh and hardened concrete". Research Report No. 1117-3F. Guidelines for Proper Use of Superplasticizers and the Effect of Retempering Practices on Performance and Durability of Concrete. Texas State Department of Highways and Public Transportation In Cooperation with the U.S. Department of Transportation Federal Highway Administration, USA, October 1989.

5. Lazniewska-Piekarczyk B: "The effect of superplasticizers and anti-foaming agents on the air entrainment and properties of the mix of self-compacting concrete". Article in Cement, Wapno, Beton. May 2009 [Online] https://www.researchgate.net/publication/287164082 [Accessed on 29.1.2019]

6. Łaźniewska-Piekarczyk B, Szwabowski J \& Miera P: "Superplasticizer compatibility problem with innovative air-entraining multicomponent Portland cement". Proceedings, $14^{\text {th }}$ International Congress on the Chemistry of Cement (ICCC 2015), Beijing, China, Oct. 13-16, 2015. [Online] https://www.researchgate.net/publication/290392716 [Accessed on 3.10.2018]

7. Kubens S: "Interaction of cement and admixtures and its influence on rheological properties". Cuvillier Verlag, Inhaberin Annette Jentzsch-Cuvillier, Nonnenstieg 8, 37075 Göttingen, Germany, 2010. [Online] https://cuvillier.de/de/shop/publications/752 [Accessed on 29.1.2019]

8. Rath S \& Ouchi M:. "Effective Mixing Method for Stability of Air Content in Fresh Mortar of Self-Compacting Concrete in Terms of Air Diameter". Internet Journal for Society for Social Management Systems, Issue 10, Vol. 1. 2015, sms15-6550.

9. Eickschen E \& Müller C: "Interactions of air-entraining agents and plasticizers in concrete". Concrete Technology Reports 2010 - 2012. VDZ gGmbH (Hrsg.). Düsseldorf, Germany, 2012. [Online] https://www.vdz-online.de/en/publications/concrete-technologyreports/ [Accessed on 29.1.2019]

10. Al-Neshawy F \& Punkki J: "Securing the stable protective pore system of concrete Report for 'Robust Air'”. Research Project, Aalto University publication series Science + Technology, No. 10, 2017, Aalto University, Helsinki, Finland. Online at: https://aaltodoc.aalto.fi/handle/123456789/28893

11. Finnish Transport Agency: "P-rate method for frost-resistant concrete in Finnish bridges". (In Finnish). Report 22/2016, Helsinki, Finland, 2016. [Online] https://julkaisut.liikennevirasto.fi/pdf8/lo_2016-22_siltabetonien_plukumenettely_web.pdf [Accessed on 4.10.2018]

12. SFS-EN 12350-7:2009 "Testing fresh concrete. Part 7: Air content. Pressure methods". Finnish Association of Construction Product Industries, SFS, Helsinki, Finland, 2009.

13. ASTM C138 / C138M-17a "Standard Test Method for Density (Unit Weight), Yield, and Air Content (Gravimetric) of Concrete". ASTM International, West Conshohocken, PA, USA, 2017, www.astm.org

14. SFS-EN 12350-2:2009 “Testing fresh concrete. Part 2: Slump-test”. Finnish Association of Construction Product Industries, SFS, Helsinki, Finland, 2009.

15. SFS-EN 12350-5:2009 "Testing fresh concrete. Part 5: Flow table test". Finnish Association of Construction Product Industries, SFS, Helsinki, Finland, 2009. 